Ferrata Storti Foundation

\title{
2-Bromopalmitate targets retinoic acid receptor alpha and overcomes all-trans retinoic acid resistance of acute promyelocytic leukemia
}

Haematologica 2019

Volume 104(1):102-112

\section{Correspondence:}

stove@shsmu.edu.cn or chengq@shsmu.edu.cn

Received: February 25, 2018.

Accepted: July 30, 2018.

Pre-published: August 3, 2018.

doi:10.3324/haematol.2018.191916

Check the online version for the most updated information on this article, online supplements, and information on authorship \& disclosures: www.haematologica.org/content/104/1/102

\section{(C)2019 Ferrata Storti Foundation}

Material published in Haematologica is covered by copyright. All rights are reserved to the Ferrata Storti Foundation. Use of published material is allowed under the following terms and conditions:

https://creativecommons.org/licenses/by-nc/4.0/legalcode. Copies of published material are allowed for personal or internal use. Sharing published material for non-commercial purposes is subject to the following conditions:

https://creativecommons.org/licenses/by-nc/4.0/legalcode, sect. 3. Reproducing and sharing published material for commercial purposes is not allowed without permission in writing from the publisher.
Ying Lu, ${ }_{1}^{1}$ Jin-Song Yan, ${ }^{2}$ Li Xia, ${ }^{1}$ Kang Qin, ${ }^{1}$ Qian-Qian Yin, ${ }^{3}$ Hong-Tao $X u,{ }^{3}$ Meng-Qing Gao, ${ }^{2}$ Xiao-Ning Qu, ${ }^{2}$ Yu-Ting Sun ${ }^{2}$ and Guo-Qiang Chen ${ }^{1}$

${ }^{1}$ Department of Pathophysiology, Key Laboratory of Cell Differentiation and Apoptosis of the Chinese Ministry of Education, Shanghai Jiao Tong University School of Medicine (SJTU-SM); ${ }^{2}$ Department of Hematology, Dalian Key Laboratory of Hematology, Liaoning Medical Center for Hematopoietic Stem Cell Transplantation, the Second Hospital of Dalian Medical University and ${ }^{3}$ Shanghai Institute for Advanced Immunochemical Studies, ShanghaiTech University, China

$Y L, J S Y$ and $L X$ contributed equally to this work.

Tatty acid oxidation dependency of leukemia cells has been docu-

$\mathrm{F}$ mented in recent studies. Pharmacologic inhibition of fatty acid oxidation, thereby, displays significant effects in suppressing leukemia. 2-Bromopalmitate, a palmitate analogue, was initially identified as an inhibitor of fatty acid oxidation, and recently recognized as an inhibitor of protein palmitoylation. However, the effects of 2-Bromopalmitate on leukemia and its cellular targets remain obscure. Herein, we discover in cultured cell lines, a transplantable mouse model, and primary blasts that 2-Bromopalmitate presents synergistic differentiation induction with alltrans retinoic acid in acute promyelocytic leukemia. Moreover, 2Bromopalmitate overcomes all-trans retinoic acid resistance in all-trans retinoic acid-resistant cells and leukemic mice. Mechanistically, 2Bromopalmitate covalently binds at cysteine 105 and cysteine 174 of retinoic acid receptor alpha $(R A R \alpha)$ and stabilizes RAR $\alpha$ protein in the presence of all-trans retinoic acid which is known to induce RAR $\alpha$ degradation, leading to enhanced transcription of RAR $\alpha$-target genes. Mutation of both cysteines largely abrogates the synergistic effect of 2Bromopalmitate on all-trans retinoic acid-induced differentiation, demonstrating that 2-Bromopalmitate promotes all-trans retinoic acidinduced differentiation through binding RAR $\alpha$. All-trans retinoic acidbased regimens including arsenic trioxide or chemotherapy, as preferred therapy for acute promyelocytic leukemia, induce adverse events and irreversible resistance. We expect that combining all-trans retinoic acid with 2-Bromopalmitate would be a promising therapeutic strategy for acute promyelocytic leukemia, especially for overcoming all-trans retinoic acid resistance of relapsed acute promyelocytic leukemia patients.

\section{Introduction}

It is increasingly recognized that fatty acid oxidation (FAO) plays an important role in supporting cell growth of many cancers including leukemia. ${ }^{1,2}$ Accordingly, inhibition of FAO by chemical compounds has yielded remarkable effects in suppressing cell growth, inducing apoptosis and relieving chemo-resistance, and thus holds therapeutic potential for leukemia..$^{3-6} 2$-Bromopalmitate (2BP), a palmitate analogue, was initially identified as an inhibitor of FAO around 50 years ago.,8 Mechanistically, 2BP inhibits carnitine palmitoyltransferase-1(CPT1) and suppresses the transfer of fatty acyl into mitochondria for oxidation. ${ }^{7}$ Over the past decade, $2 \mathrm{BP}$ has often been referenced as being a general inhibitor of protein palmitoylation through covalent binding to protein acyl transferases (PAT). ${ }^{9,10}$ More recently, 2BP was demonstrated to modulate differentiation of neural stem cell and osteoblast 
which involved protein palmitoylation and histone acetylation. ${ }^{11-13}$ Overall, the effects of $2 \mathrm{BP}$ on leukemia and its cellular targets remain obscure.

Acute promyelocytic leukemia (APL) is a M3 subtype of acute myeloid leukemia(AML) genetically characterized by chromosome translocations involving retinoic acid receptor $\alpha(R A R \alpha)$ on chromosome 17 and promyelocytic leukemia $(P M L)$ on chromosome 15, which generates the oncogenic PML-RAR $\alpha$ fusion protein. ${ }^{14-17} \mathrm{RAR} \alpha$ is a ligand-dependent transcription factor that binds as heterodimers with retinoid X receptor (RXR) to their target response elements and plays pivotal roles in a series of physiological processes including cell growth, differentiation, survival, and death. The PML-RAR $\alpha$ fusion protein, however, acts as a transcriptional repressor of RAR $\alpha$-target genes and results in maturation arrest of myeloid progenitors at the promyelocytic stage. ${ }^{15,18}$

All-trans retinoic acid (ATRA), a natural ligand for RAR, is the first Food and Drug Administration-approved drug for APL differentiation, which degrades PML-RAR $\alpha$ complex through caspases-dependent or proteasome pathway. Combinations of ATRA, arsenic trioxide (ATO) or chemotherapy were developed and have dramatically improved the complete remission (CR) rate and survival time of APL patients. ${ }^{15,19-21}$ However, current ATRA-based regimens may cause adverse events including fatal retinoic acid syndrome, systemic infection or secondary leukemia. ${ }^{15,22,23}$ In addition, $5-10 \%$ of APL patients fail to respond to the therapy targeting PML-RAR $\alpha$ or relapse after CR. ${ }^{24}$ More recently, resistance to ATO in APL was reported by several groups. ${ }^{24-26}$ Therefore, it is essential to further optimize ATRA-based therapy for better prognosis of de novo or relapsed APL patients. In the present study, 2BP was identified to present synergistic differentiation induction with ATRA in APL cells and murine model. Moreover, 2BP overcomes ATRA resistance in ATRA-resistant cells and leukemic mice. We expected that 2BP would be a promising candidate for APL therapy, especially for overcoming ATRA resistance of relapsed APL patients.

\section{Methods}

\section{Patients and cells}

Bone marrow samples were collected from 11 cases of newly diagnosed APL patients at the Department of Hematology of the Second Hospital of Dalian Medical University. Patients were diagnosed according to the French-American-British classification. Detailed information of patients is listed in Table 1. Informed consent was obtained from all patients in accordance with the Declaration of Helsinki, and all manipulations were approved by the Medical Science Ethic Committee of Dalian Medical University. Mononuclear cells were isolated by density gradient centrifugation using Lymphoprep, and cryopreserved. In addition, 3 potential donors for allogeneic bone marrow transplantation were used to purify normal healthy hematopoietic cells. Human CD34+ cells were enriched from bone marrow mononuclear cells using MiniMACS (Miltenyi Biotech, Bergisch Gladbach, Germany) following the manufacturer's instructions. ${ }^{27}$ Confirmation of CD34 cells' phenotype and purity was assessed by flow cytometry analysis using CD34-PE-Cy7 (BD Biosciences, San Diego, CA). Purified CD34+ cells were grown in serum-free hematopoietic growth medium (HPGM; Lonza) supplemented with $10 \mathrm{ng} / \mathrm{mL}$ recombinant human interleukin-3 (rhIL-3), 10 $\mathrm{ng} / \mathrm{mL}$ rhIL-6 and $50 \mathrm{ng} / \mathrm{mL}$ recombinant human stem cell factor (PeproTech). The primary APL cells, AML cell lines NB4, HL60, NB4-MR2, NB4-LR1, and NB4-LR2 were maintained in RPMI 1640 medium (Sigma-Aldrich, St Louis, MO), supplemented with $10 \%$ heat-inactivated fetal bovine serum (FBS; Gibco BRL) in a humidified incubator at $37{ }^{\circ} \mathrm{C}$ and $5 \% \mathrm{CO} 2 / 95 \%$ air (v/v).

\section{Reagents and antibodies}

ATRA, arsenic trioxide, 2-Bromopalmitate(2BP), palmitate acid (PA), 16BP and 12BP, DNase-free RNase A and propidium iodide were obtained from Sigma. Rabbit polyclonal antibodies against RAR $\alpha, R X R \alpha$, Vinculin and PML were obtained from Santa Cruz Biotechnology (Santa Cruz). Rabbit polyclonal antibodies against pyruvate kinase M2(PKM2) and $\beta$-actin were obtained from Cell Signaling Technology. Anti-PML-RAR $\alpha$ fusion antibody was from Abcam.

Table 1. Patient data and response to $2 \mathrm{BP}$ and/or ATRA.

\begin{tabular}{|c|c|c|c|c|c|c|c|c|c|c|}
\hline \multirow[b]{2}{*}{ No. } & \multirow[b]{2}{*}{$\operatorname{Sex}$} & \multirow[b]{2}{*}{ Age(vears) } & \multirow[b]{2}{*}{ Chromosome } & \multirow[b]{2}{*}{ Blast } & \multirow[b]{2}{*}{ WBC $\left(x 10^{\circ} / L\right)$} & \multirow[b]{2}{*}{ Vehicle } & \multicolumn{3}{|c|}{ CD11b positive cells\% } & \multirow[t]{2}{*}{$\mathbf{P}$} \\
\hline & & & & & & & $2 B P$ & ATRA & ATRA/2BP & \\
\hline 1 & M & 26 & ND & $60.00 \%$ & 37.88 & $2.10 \pm 0.72$ & $2.78 \pm 0.35$ & $31.30 \pm 2.12$ & $59.11 \pm 2.44$ & $<0.001$ \\
\hline 2 & $\mathrm{~F}$ & 33 & ND & $58.50 \%$ & 11.21 & $0.40 \pm 0.31$ & $1.80 \pm 0.74$ & $34.17 \pm 0.77$ & $61.65 \pm 0.93$ & $<0.01$ \\
\hline 3 & M & 40 & ND & $92.00 \%$ & 37.55 & $2.80 \pm 0.93$ & $3.01 \pm 0.89$ & $36.56 \pm 2.33$ & $60.40 \pm 0.69$ & $<0.05$ \\
\hline 4 & M & 43 & $\begin{array}{l}46, X Y, t(15 ; 17) \\
\text { (q22;q12) }\end{array}$ & $69.50 \%$ & 1.3 & $1.10 \pm 0.17$ & $1.42 \pm 0.43$ & $38.28 \pm 2.90$ & $65.02 \pm 4.13$ & $<0.001$ \\
\hline 5 & $\mathrm{~F}$ & 43 & ND & $89.70 \%$ & 3.16 & $3.04 \pm 0.11$ & $12.8 \pm 0.11$ & $33.13 \pm 1.25$ & $57.83 \pm 3.02$ & $<0.05$ \\
\hline 6 & M & 53 & $\begin{array}{l}46, \mathrm{XY},-8,+22, \mathrm{t}(15 ; 17) \\
(\mathrm{q} 22 ; \mathrm{q} 12)\end{array}$ & $77.00 \%$ & 17.42 & $0.25 \pm 0.19$ & $5.11 \pm 0.38$ & $29.51 \pm 0.22$ & $59.66 \pm 1.51$ & $<0.001$ \\
\hline 7 & M & 60 & $\begin{array}{l}46, X Y,+10, i(11 q) \\
-13,-14, t(15 ; 17)(q 22 ; q 12)\end{array}$ & $87.50 \%$ & 4.73 & $19.8 \pm 2.22$ & $19.44 \pm 2.30$ & $61.55 \pm 4.13$ & $75.18 \pm 5.50$ & $<0.01$ \\
\hline 8 & M & 17 & 46,XY,t(15;17)(q22;q12) & $89.37 \%$ & 1.05 & $14.52 \pm 2.44$ & $16.22 \pm 1.90$ & $41.85 \pm 1.55$ & $48.20 \pm 2.13$ & $>0.05$ \\
\hline 9 & $\mathrm{~F}$ & 26 & $46, \mathrm{XX}$ & $88.50 \%$ & 2.2 & $1.40 \pm 0.50$ & $1.07 \pm 0.92$ & $29.75 \pm 1.73$ & $31.22 \pm 1.51$ & $>0.05$ \\
\hline 10 & M & 63 & ND & $92.00 \%$ & 5.29 & $8.80 \pm 1.33$ & $10.51 \pm 1.55$ & $46.25 \pm 3.01$ & $45.11 \pm 0.73$ & $>0.05$ \\
\hline 11 & $\mathrm{M}$ & 67 & $46, \mathrm{XY}, \mathrm{t}(15 ; 17)(\mathrm{q} 22 ; \mathrm{q} 12)$ & $56.00 \%$ & 1.6 & $12.80 \pm 1.23$ & $11.85 \pm 1.87$ & $45.87 \pm 0.30$ & $40.33 \pm 1.33$ & $>0.05$ \\
\hline
\end{tabular}

Mononuclear cells from bone marrow of 11 APL patients were isolated by density gradient centrifugation using Lymphoprep and maintained in RPMI 1640 medium supplemented with $10 \%$ FBS. The cells were treated with $10 \mu \mathrm{M} 2 \mathrm{BP}$ and/or $10^{7} \mathrm{M}$ ATRA for 3 days and CD11b-positive cells were counted by flow cytometry. ND indicates not done. $P$ : $P$ value between ATRA and ATRA/2BP. 


\section{Wright-Giemsa staining}

Wright-Giemsa staining kit was from BASO Diagnostic (Zhuhai, China). Briefly, the cytospin slides were prepared and solution A was added onto cells for 3-5 mins followed by solution $\mathrm{B}$ for $1 \mathrm{~min}$. The slide was then washed under running water. Images were taken under inverted microscope ${ }^{28}$ The images were quantified according to the shape of the nuclei $(0=$ round, $1=$ curveted, $2=$ polylobulated). The score of each figure was calculated and normalized by counted cell number. The counting of leukemic cells was made on at least 100 cells from three independent experiments.

\section{Establishment and analysis of transplantation} leukemic mice

Splenocytes isolated from leukemic PML-RAR $\alpha$ or mutant
PML-RAR $\alpha$ transgenic mice were injected into 6- to 8-week-old female $\mathrm{FVB} / \mathrm{N}$ mice intravenously after sublethal irradiation. ${ }^{29}$ Two days after transplantation, the mice were treated with vehicle, 2BP, ATRA, ATO, or combination of these compounds. The peripheral blood $(\mathrm{PB})$ and bone marrow $(\mathrm{BM})$ cells were collected for morphological analysis. The spleen and liver were isolated for hematoxylin and eosin staining. Animal handling was approved by the committee for humane treatment of animals at Shanghai Jiao Tong University School of Medicine.

\section{Statistical analysis}

Statistical analyses between the control and treatment groups were performed by standard two-tailed Student's $t$-test. All experiments were repeated at least three times. A value of $P<0.05$ was considered to be statistically significant.
A<smiles>CCCCCC(Br)C(=O)O</smiles>

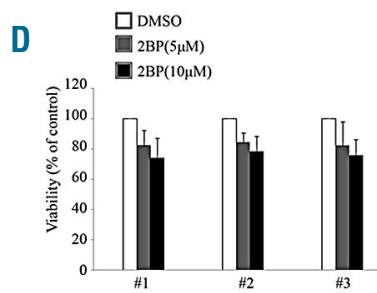

G

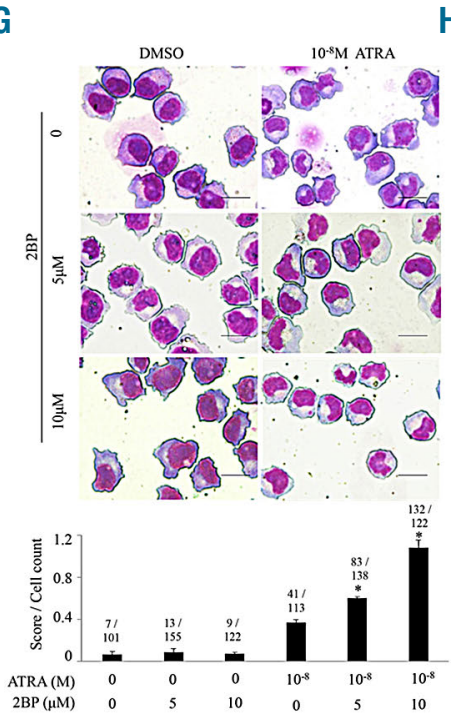

B

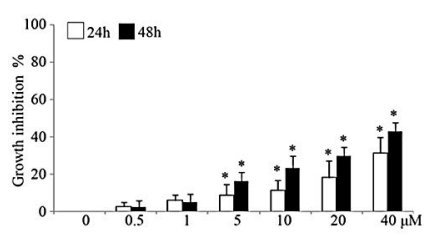

E

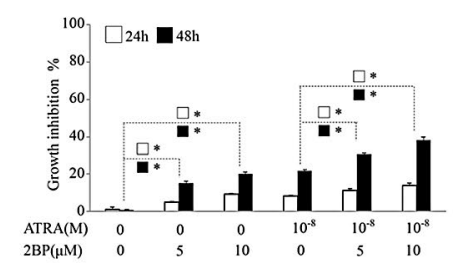

$\mathrm{H}$

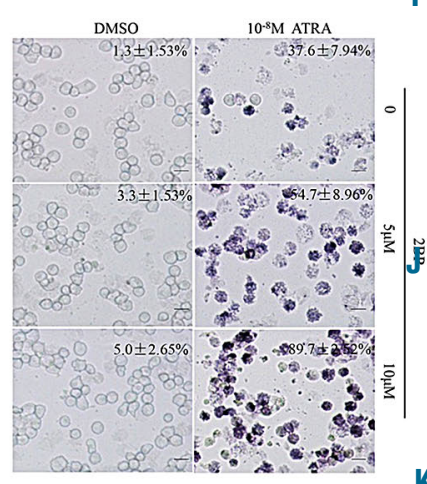

C

F

I
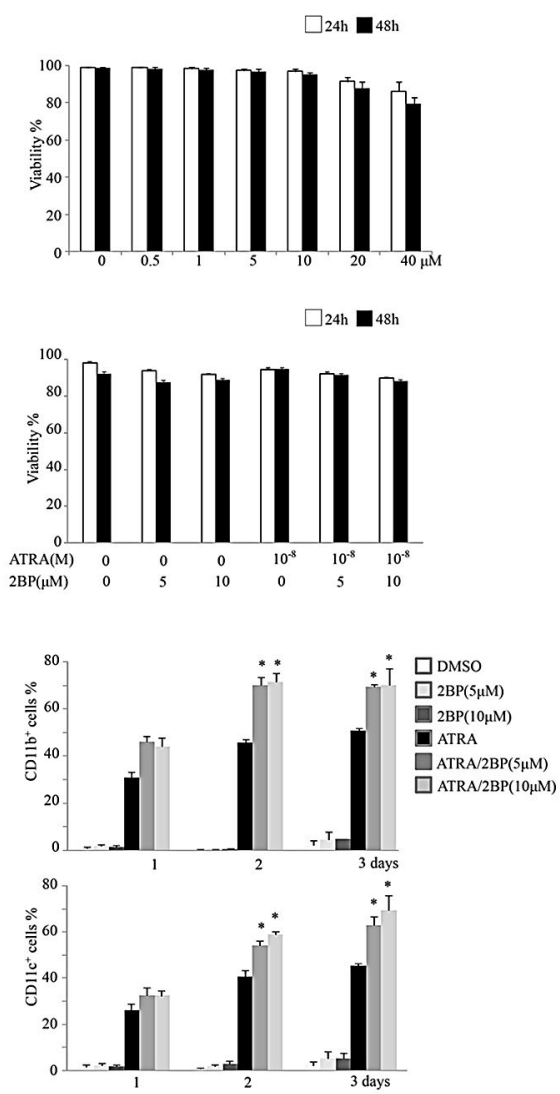

K

Figure 1. 2BP enhances ATRA-induced cell differentiation in APL cell lines. (A) Chemical structure of 2-Bromopalmitate (2BP). (B-C) NB4 cells were treated with different concentrations of 2BP for 24 and 48 hours, and growth inhibition and cell viability \% were evaluated by trypan-blue exclusion assay. $* P<0.05$ against vehicletreated group. (D) Effects of 2BP on CD34+ bone marrow mononuclear cells isolated from 3 healthy donors (\#1, \#2 and \#3) are shown. (E-F) NB4 cells were incubated with 5 or $10 \mu \mathrm{M} 2 \mathrm{BP}$ and/or $10^{-8} \mathrm{M}$ ATRA for the indicated hours and growth inhibition (E) and cell viability \% (F) were evaluated by trypan-blue exclusion assay. $\star P<0.05$ between the line-pointed group. (G-K) NB4 cells were incubated with 5 or $10 \mu \mathrm{M} 2 \mathrm{BP}$ and/or $10^{-8} \mathrm{M}$ ATRA for the indicated days and Wright's staining morphology $(\mathrm{G})$, NBT reduction(H), CD11b-(I), CD11C-(J) and CD15-positive(K) cells counted by flow cytometry are shown. Scale bars are 20 um. The images of Wright's staining $(G)$ were further quantified according to the shape of nuclei $(0=$ round, $1=$ curveted, $2=$ polylobulated). The score of each figure was calculated, normalized by cell number (counted from three independent experiments) and shown at the bottom. The ratio shows the total score/number of cells counted in each condition. $\star P<0.05$ against ATRA-treated group. All values for percentage of NBT-positive cells represent means \pm s.d. of triplicate samples in an independent experiment. All experiments were repeated at least three times with the same results. 


\section{Results}

2BP enhances differentiation induction of ATRA in APL cell lines and primary blasts from APL patients

ATRA-sensitive NB4 cells were treated with different concentrations of 2BP (Figure 1A) and cell growth was determined. $2 \mathrm{BP}$ inhibited cell growth in a concentrationdependent manner (Figure 1B), with an increased percentage of cells at the G1 stage (Online Supplementary Figure S1). 2BP treatment induced a slight decrease of cell viability at $40 \mu \mathrm{M}$ in NB4 cells (Figure 1C). The effects of 2BP on normal $\mathrm{CD} 34^{+}$hematopoietic cells purified from bone marrow samples of 3 healthy donors were also assessed. The viability of $\mathrm{CD} 34^{+}$hematopoietic cells in the 2BPtreated group was comparable with that in the vehicletreated group (Figure 1D). Next, we assessed the cellular effects of $2 \mathrm{BP}$ in combination with ATRA. As depicted in Figure $1 \mathrm{E}$ and $\mathrm{F}$, the $2 \mathrm{BP}$ and ATRA combination synergistically induced growth arrest without inducing apparent apoptosis (Online Supplementary Figure S2). Intriguingly, $2 \mathrm{BP}$ alone at nontoxic concentrations $5 \mu \mathrm{M}$ or $10 \mu \mathrm{M}$ did not induce apparent differentiation of NB4 cells, but it significantly increased ATRA-induced granulocytic differentiation, as evidenced by mature granulocytic morphologic features (such as smaller cell size, reduced nucleus-cytoplasm ratio, condensed chromatin, curveted or polylobulated nuclei) (Figure 1G), increased NBT reduction (Figure $1 \mathrm{H}$ ), and percentage of CD11b (Figure 1I), CD11c (Figure 1J) and CD15 (Figure 1K) cells. Quantitative analysis based on the shape of nuclei demonstrated more mature granulocytic cells upon combination of 2BP with ATRA (bottom panel, Figure 1G). Notably, cotreatment of $2 \mathrm{BP}$ with ATRA also increased the percentage of CD11b and CD11c positive cells in another APL cell line, HL60 (Online Supplementary Figure S3). More importantly, the synergistic effect exhibited by the use of $2 \mathrm{BP}$ and ATRA combination in differentiation could also be seen in primary blasts from APL patients. The percentage of CD11b-positive cells treated with ATRA and 2BP was significantly increased in 7 out of 11 samples compared with the ATRA-treated group (Table 1). Notably, two APL samples with complex chromosome abnormalities (No. 6 and No. 7) which usually do not respond well to ATRA-based therapy displayed significant differentiation under treatment with ATRA and 2BP. Collectively, these data demonstrated that 2BP presents a synergistic differentiation-enhancing effect in APL cells when used in combination with ATRA.

As mentioned above, combination of ATO with ATRA have dramatically improved the CR rate of APL patients, and is now used as a frontline treatment of APL. $15,19,20$ Therefore, we further evaluated the effect of the combination of ATO and 2BP on NB4 cells by flow cytometry. As shown in Online Supplementary Figure S4A, upon treatment of ATO/2BP, the expression of CD11b and CD11c was significantly increased on day 2 and day 3 compared with ATO-treated cells. Moreover, addition of 2BP enhanced the granulocytic differentiation of NB4 cells induced by ATRA/ATO (Online Supplementary Figure S4A). These data
A

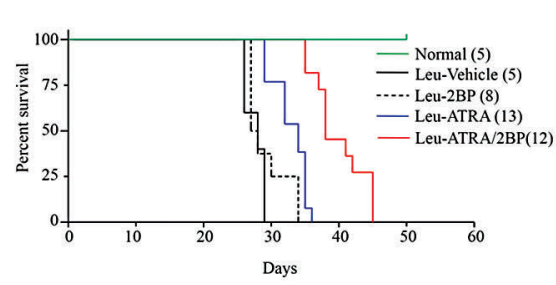

c

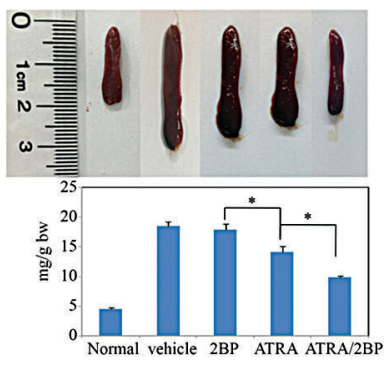

B

D
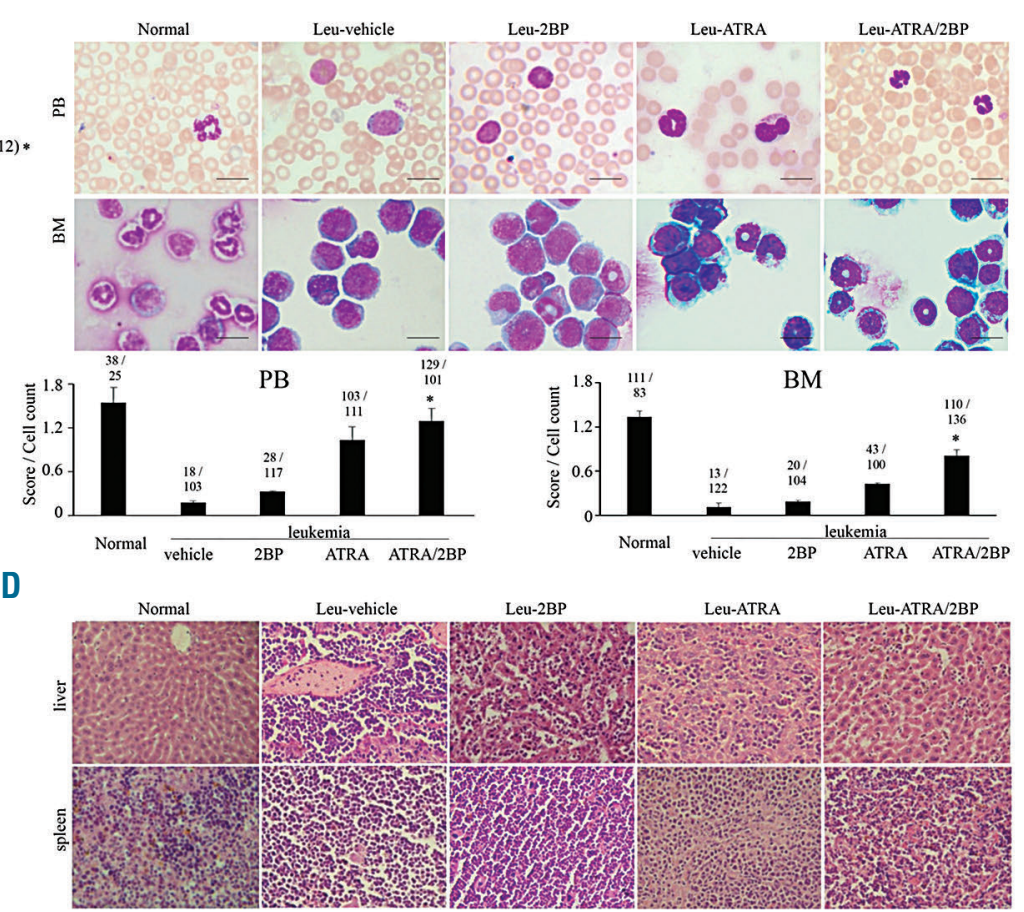

Figure 2. 2BP enhances ATRA-induced APL cell differentiation in vivo. ATRA-sensitive leukemic (leu) mice were treated with vehicle $(5 \%$ DMSO, $5 \%$ cremophor, $90 \%$ saline), 2BP (5 mg per $\mathrm{kg}$ body weight, intraperitoneally), ATRA (10 mg per kg body weight, intraperitoneally) or ATRA/2BP daily for five continuous days a week Normal FVB/N mice were taken as negative controls. When the first vehicle-treated leukemic mice were moribund, all mice were killed and analyzed. (A) The survival (\%) and lifetime (day) of leukemic mice in each group were recorded and Kaplan-Meier survival analysis was shown. The numbers of mice are indicated in parentheses, and $* P<0.05$ against ATRA-treated mice. (B) Cytologic analysis of peripheral blood (PB) and bone marrow (BM) cells derived from different agent-treated mice by Wright's staining. Scale bars are $20 \mu \mathrm{m}$. The images were quantified as described in Figure $1 \mathrm{G}$ and shown at the bottom. $* P<0.05$ against ATRA-treated mice. Leu represents leukemia. (C) The macroscopic appearance/the weight (mg/g bw) of spleen (top panels) are shown. Each column represents the mean with bar as s.d. of 3 mice in an independent experiment, and $\star P<0.05$ between the line-pointed group. (D) The leukemic invasions in spleen and liver were analyzed by hematoxylin and eosin (H\&E) staining. 

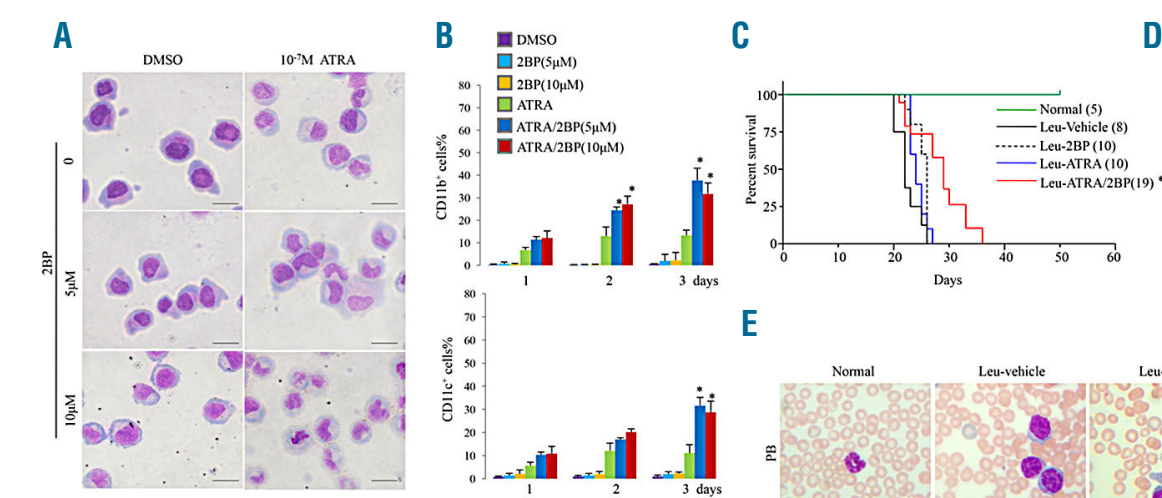

D

E
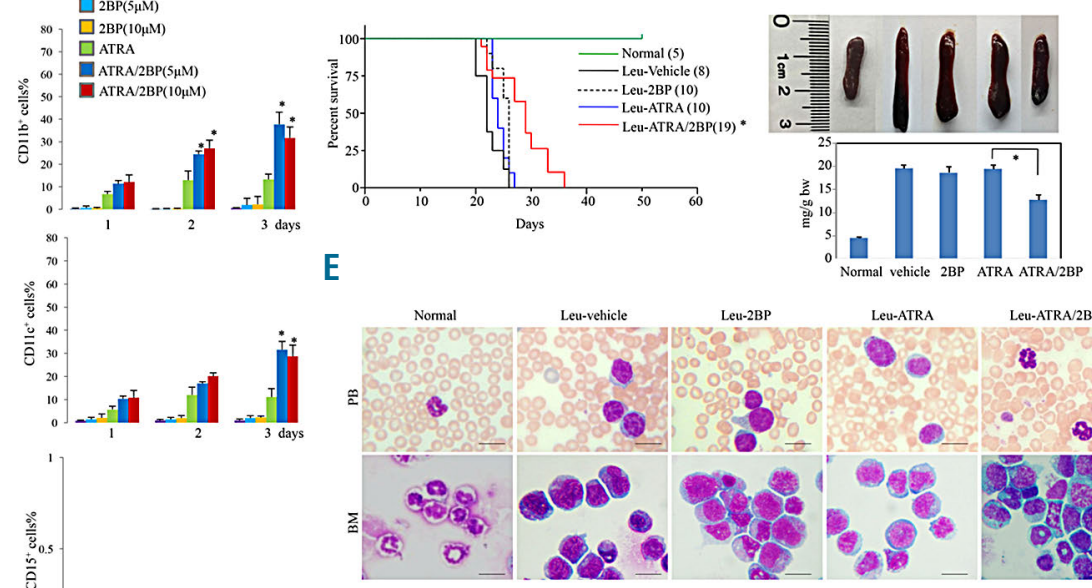

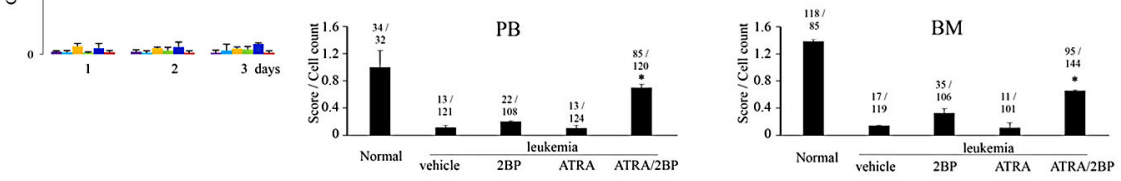

Figure 3. 2BP overcomes ATRA resistance in vitro and in vivo. (A-B) ATRA-resistant NB4-MR2 cells were treated with $5 \mu \mathrm{M}$ or $10 \mu \mathrm{M} 2 \mathrm{BP}$ in combination with ATRA for 3 days. The Wright's staining morphology (A) and percentages of CD11b (upper panel, B) and CD11c (middle panel, B) and CD15 (bottom panel, B) expression are shown. Scale bars are $20 \mu \mathrm{m}$. The images were quantified as described in Figure $1 \mathrm{G}$ and shown at the bottom. ${ }^{*} P<0.05$ against ATRA-treated group. (C-D) ATRAresistant transplantable leukemic mice (leu) were treated with vehicle, 2BP (5 mg per kg body weight, intraperitoneally), ATRA (10 mg per kg body weight, intraperitoneally) or ATRA/2BP daily for five continuous days a week. The survival (\%) and lifetime (day) of leukemic mice in each group were recorded and Kaplan-Meier survival analysis is shown (C). ${ }^{*}<0.05$ against ATRA-treated group. (D) The macroscopic appearance/the weight (mg/g bw) of spleen (top panels) are shown. Each column represents the mean with bar as s.d. of 3 mice in an independent experiment, and $* P<0.05$ between the line-pointed group. (E) Cytologic analysis PB and BM cells derived from different agent-treated mice by Wright's staining. The images were quantified as described in Figure $1 \mathrm{G}$ and shown on the bottom. * $P<0.05$ against ATRA-treated group.

indicated that $2 \mathrm{BP}$ could enhance the differentiation effect of ATO on APL cells in vitro.

\section{BP enhances differentiation induction of ATRA in vivo}

Subsequently, the effect of $2 \mathrm{BP}$ was further evaluated on transplantable APL mice. We intravenously transplanted a high dose $\left(4 \times 10^{5}\right)$ of ATRA-sensitive leukemic blasts from transgenic mice expressing human PMLRAR $\alpha$ into sublethally irradiated isogenic FVB/N recipients to generate ATRA-sensitive leukemic mice. ${ }^{30}$ Leukemic mice were treated intraperitoneally with 5 $\mathrm{mg} / \mathrm{kg}$ body weight of $2 \mathrm{BP}$ with or without ATRA on day 2 after transplantation. Twenty-five days after transplantation, mice in the vehicle group started to be frail and sluggish, and rapidly died off in the following 3 days. The lifetime of mice in ATRA-treated group lasted as long as 35 days. In contrast, $2 \mathrm{BP}$ combined with ATRA extended lifetime and survival of leukemic mice to 45 days (Figure 2A). Consistently, more morphologically differentiated cells were observed in peripheral blood $(\mathrm{PB})$ and bone marrow $(\mathrm{BM})$ of leukemic mice that received ATRA and ATRA/2BP (Figure $2 B$ ). Further quantitative analysis based on the shape of nuclei showed more mature granulocytic cells upon combination of 2BP with ATRA (bottom panel, Figure 2B). In addition, enlarged spleens were found in vehicle-treated mice, which could be alleviated when treated with ATRA or ATRA/2BP (Figure 2C). Histological examination revealed that ATRA/2BP treatment inhibited the infiltration of leukemia cells into the spleen and liver (Figure $2 \mathrm{D})$. These results suggested that the leukemic infiltration to spleen was reduced in presence of $2 \mathrm{BP}$. Taken together, these data demonstrated the potential of 2BP to synergistically induce the maturation of promyelocytes with ATRA in vivo.

In addition, we evaluated the effect of $2 \mathrm{BP}$ on ATO in APL murine model. ${ }^{31}$ Consistent with the in vitro data (Online Supplementary Figure S4A), administration of ATO/2BP extended the survival of leukemic mice compared to that in the ATO-treated group Online Supplementary Figure S4B). These data supported that 2BP enhanced the effect of ATO on APL in vivo. In addition the lifespan of leukemic mice that received ATRA/ATO/2BP is comparable to that when treated with ATRA/ATO (Online Supplementary Figure S4B). The effect of $2 \mathrm{BP}$ on the combination of ATRA/ATO deserves further evaluation.

To evaluate the in vivo acute toxicity and identify a clinically relevant dose of $2 \mathrm{BP}$ in mice, the maximum tolerated dose (MTD) was determined. ${ }^{32}$ Athymic nude mice were injected intraperitoneally with a single dose of $2 \mathrm{BP}$ at $50,100,200 \mathrm{mg} / \mathrm{kg} / \mathrm{dose}$. At $100 \mathrm{mg} / \mathrm{kg}$, treated mice were alive at day 14 , whereas at $200 \mathrm{mg} / \mathrm{kg}$, the mice died on day 2 , suggesting that the best-tolerated concentration of $2 \mathrm{BP}$ is $100 \mathrm{mg} / \mathrm{kg}$.

\section{BP induces the differentiation of ATRA-resistant APL in vitro and in vivo}

Since ATRA resistance has been a major obstacle in clinical APL therapy, the ATRA/2BP combination was also designed to be examined to relieve ATRA resistance. NB4derived subclones, including NB4-MR2, NB4-LR1 and NB4-LR2 were tested. In accordance with previous reports, these subclones were refractory to ATRA-induced matura- 

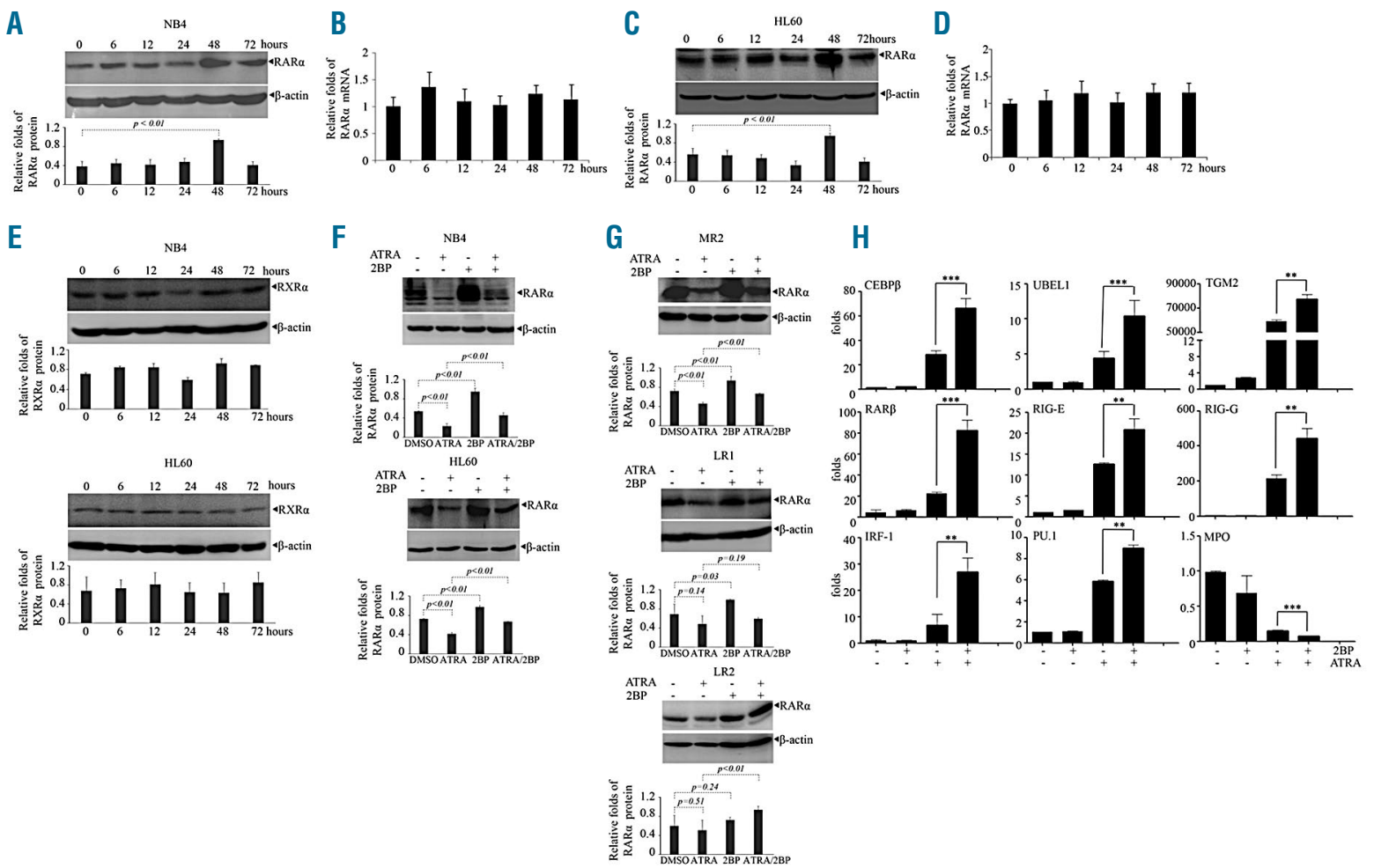

Figure 4. $2 B P$ stabilizes RAR $\alpha$ protein and enhances transcriptional activity of RAR $\alpha$. (A-D) NB4(A-B) and HL6O(C-D) cells were incubated with $5 \mu \mathrm{M}$ of $2 B P$ for indicated hours. The mRNA (B and D) and protein ( $A$ and $C$ ) of RAR $\alpha$ were detected by quantitative real-time PCR and western blots. $\beta$-actin was detected as the loading control. $P$ value between the line-pointed group is shown. (E) NB4 and HL60 cells were incubated with $5 \mu \mathrm{M}$ of 2BP for indicated hours and protein of RXR $\alpha$ was detected by western blot with $\beta$-actin as the loading control. (F-G) ATRA-sensitive NB4 and HL60 (F) or ATRA-resistant NB4-MR2, NB4-LR1, and NB4-LR2 cells (G) were treated with $5 \mu \mathrm{M} 2 \mathrm{BP}$ in the presence or absence of ATRA for 48 hours and RAR $\alpha$ protein was detected by western blot. The protein bands on the gels were quantified by densitometry from three independent experiments and shown in the bottom panel (A,C,E,F and G). Scanning was performed at optimal exposure time where band intensity was proportional to the concentration of protein present. Gel photographic images were stored as GRAYSCALE pictures in TIF format and were processed using ImageJ Software. $P$ value between the line-pointed group is shown. (H) NB4 cells were treated with $5 \mu \mathrm{M} 2 \mathrm{BP}$ and/or $10^{8} \mathrm{M}$ ATRA for 48 hours, and the expression of indicated genes was detected by quantitative real-time PCR with specific primers. ** and *** indicated $P$ value between 2BP plus ATRA and ATRA was $<0.01$ and $<0.001$, respectively. Each experiment was repeated three times.

tion (Figure 3A and Online Supplementary Figure S5). In contrast, ATRA combined with 2BP could induce granulocytic differentiation of NB4-MR2 (Figure 3A-B), NB4-LR1 and NB4-LR2 (Online Supplementary Figure S5) cells as evidenced by mature granulocytic morphologic features and increased CD11b and CD11c expression, indicating that 2BP could overcome ATRA resistance of promyelocytes.

In vivo, ATRA-resistant leukemic blasts from transgenic mice expressing human MRP8-PML-RAR $\alpha$ mutant were intravenously transplanted into sublethally irradiated isogenic FVB/N recipients to generate ATRA-resistant leukemic mice. ${ }^{33}$ Twenty-six days later, all vehicle-treated leukemic mice died abruptly (Figure 3C). ATRA-treated leukemic mice died in 27 days, verifying that the ATRA resistance was lethal for leukemic mice. In contrast, administration of $2 \mathrm{BP}$ along with ATRA overcame the resistance and extended the survival of leukemic mice to 36 days (Figure $3 \mathrm{C}$ ). It was discovered that 2BP with ATRA facilitated the remission of swollen spleen on ATRA-resistant leukemic mice (Figure 3D). Consistent with this, more morphologically differentiated cells were observed in $\mathrm{PB}$ and $\mathrm{BM}$ in the ATRA/2BP-treated group (Figure $3 \mathrm{E}$ ). These data indicated that $2 \mathrm{BP}$ presents a potential to overcome ATRA resistance.

\section{BP accumulates RAR $\alpha$ protein and enhances} ATRA-dependent transcriptional activity of RAR $\alpha$

As previously documented, administration of ATRA induced a progressive degradation of wild-type $\operatorname{RAR} \alpha$ as well as the PML-RAR $\alpha$ chimeric protein. ${ }^{14,15}$ To elucidate the mechanism of the positive effect of $2 \mathrm{BP}$ on APL cell differentiation, RAR $\alpha$ and PML-RAR $\alpha$ fusion protein in NB4 cells under 2BP treatment were detected. Treatment of 2BP for 48 hours significantly increased RAR $\alpha$ protein level (Figure 4A), but not its mRNA level in NB4 (Figure 4B) and HL60 cells (Figure 4C-D). In contrast, RXR $\alpha$, the binding partner of RAR $\alpha$ protein in transactivating target genes as heterodimers, was not affected by 2BP (Figure $4 \mathrm{E})$. Furthermore, we detected the effects of $2 B P$ on RAR $\alpha$ protein in the presence of ATRA, which was documented to induce degradation of RAR $\alpha .^{34}$ When NB4 and HL60 cells were cotreated with ATRA and 2BP, the protein level of RAR $\alpha$ was increased compared to ATRA-treated group (Figure 4F). Moreover, accumulated RAR $\alpha$ protein induced by $2 B P$ in the absence (MR2 and LR1) or presence of ATRA (MR2 and LR2) could also be seen in ATRA resistance NB4-MR2, NB4-LR1 or NB4-LR2 cells (Figure 4G). In addition, using immunofluorescent staining with antiPML antibody, we observed that ATRA restored the PML- 
A

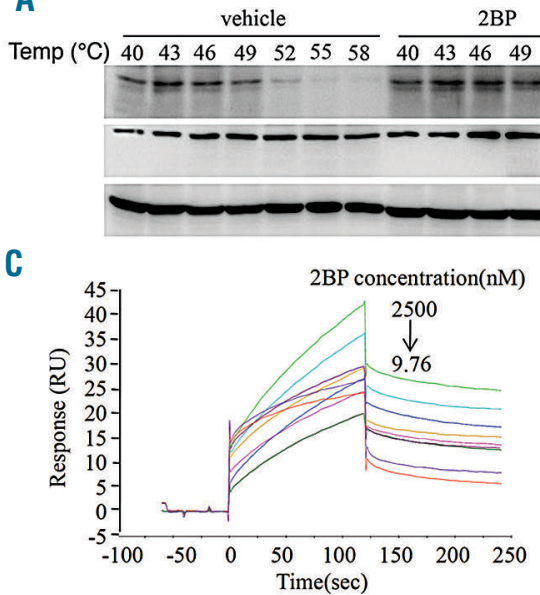

E
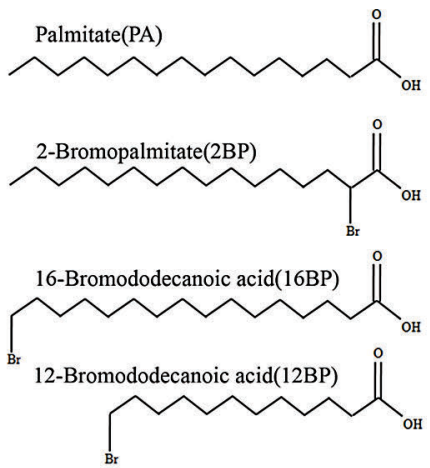

B

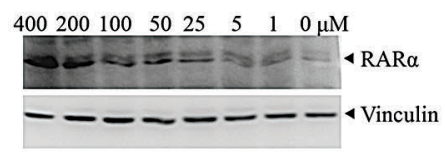

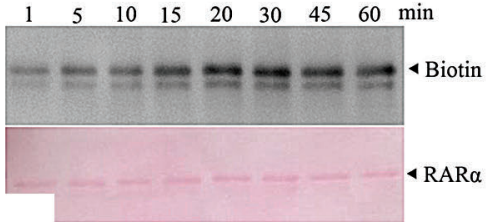

$\mathrm{F}$

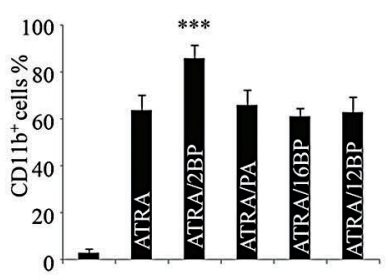

0 2BP PA 16BP 12BP

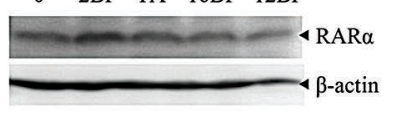

Figure 5. 2BP directly binds with RAR $\alpha$. (A-B) Cellular thermal shift assay (CETSA) was performed on NB4 cells as described in the Methods section. The effects of 2BP on RAR $\alpha$, vinculin and PKM2 at different temperatures (A) and different doses (B) were evaluated by Western blot analysis. (C) SPR analysis of the binding between 2BP and RAR $\alpha$. The recombinant RAR $\alpha$ protein was immobilized on an activated CM5 chip. $2 \mathrm{BP}$ was then flowed across the chip at increasing concentrations. (D) The recombinant RAR $\alpha$ protein was incubated with biotin-2BP for the times indicated, and the mixtures were blotted with anti-biotin antibody. The membrane stained with Ponceau S is shown on the bottom. (E-F) NB4 cells were treated with PA, 2BP, 16BP or 12BP (chemical structure shown on E) for 3 days and CD11b-positive cells were counted by flow cytometry and RAR $\alpha$ expression was detected by western blot are shown. $* * * P<0.001$ against vehicle-treated group. All experiments were repeated three times with the same results.

RAR $\alpha$-disrupted PML nuclear body, which was decreased by the addition of 2BP (Online Supplementary Figure S6A). Western blot analysis using an antibody against PMLRAR $\alpha$ fusion protein showed that 2BP could increase the amount of PML-RAR $\alpha$ in NB4 cells (Online Supplementary Figure $S 6 B$ ), suggesting that 2BP may also stabilize PML$\mathrm{RAR} \alpha$ fusion protein.

Next, we asked whether the transcriptional activity of RAR $\alpha$ protein was also enhanced by the ATRA/2BP combination following the accumulation of protein level. Consistent with previous reports, ATRA, but not 2BP, increased the expression of RAR $\alpha$ target genes including $R A R \beta$, CCAAT/enhancer-binding protein $\alpha(C / E B P \alpha)$, retinoic acid inducible gene-E (RIG-E), RIG-I, RIG-G, interferon regulatory factor $1(I R F-1)$, transglutaminase 2(TGM2), and ubiquitin-like modifier activating enzyme $7(U B E 1 L)$ gene and decreased that of myeloperoxidase $(M P O)$ in NB4 cells (Figure 4H). ${ }^{35-40}$ More intriguingly, the modulation of these expressions by ATRA was significantly enhanced by the cotreatment of 2BP with ATRA in NB4 cells (Figure 4H). Taken together, these data indicated that $2 \mathrm{BP}$ accumulates RAR $\alpha$ protein and enhances ATRAdependent transcriptional activity of RAR $\alpha$.
To further confirm the role of the stabilized RAR $\alpha$ protein in the synergistic differentiation-inducing effect of $2 \mathrm{BP}$ in combination with ATRA, AM580, a selective RAR $\alpha$ agonist, ${ }^{41}$ was applied to NB4 cells. The results showed that, similar to that seen under ATRA treatment, 2BP could enhance AM580-induced differentiation of NB4 cells (Online Supplementary Figure S7A-B). Moreover, administration of AM580 induced a loss of RAR $\alpha$ proteins, which could also be accumulated by addition of 2BP (Online Supplementary Figure S7C). On the other hand, Ro 41-5253, a highly specific RAR $\alpha$ antagonist, ${ }^{42}$ could effectively antagonize the synergistic differentiation-inducing effect of the 2BP and ATRA combination in NB4 cells (Online Supplementary Figure S7A-B). These data indicated that maintenance of $\mathrm{RAR} \alpha$ protein contributed to the enhancing effect of $2 B P$ on ATRA-induced differentiation.

\section{BP directly targets RAR $\alpha$}

2BP has been reported to be active in covalently binding target proteins because it is from the $\alpha$-halo-carbonyl group. ${ }^{10}$ To further elucidate the mechanism of $2 \mathrm{BP}$ on ATRA-induced APL differentiation, we detected the possibility of RAR $\alpha$ protein as a cellular target of $2 \mathrm{BP}$. To this 
A

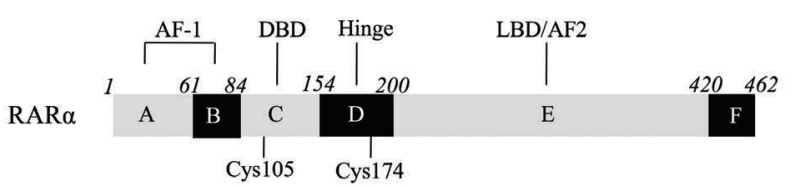

B

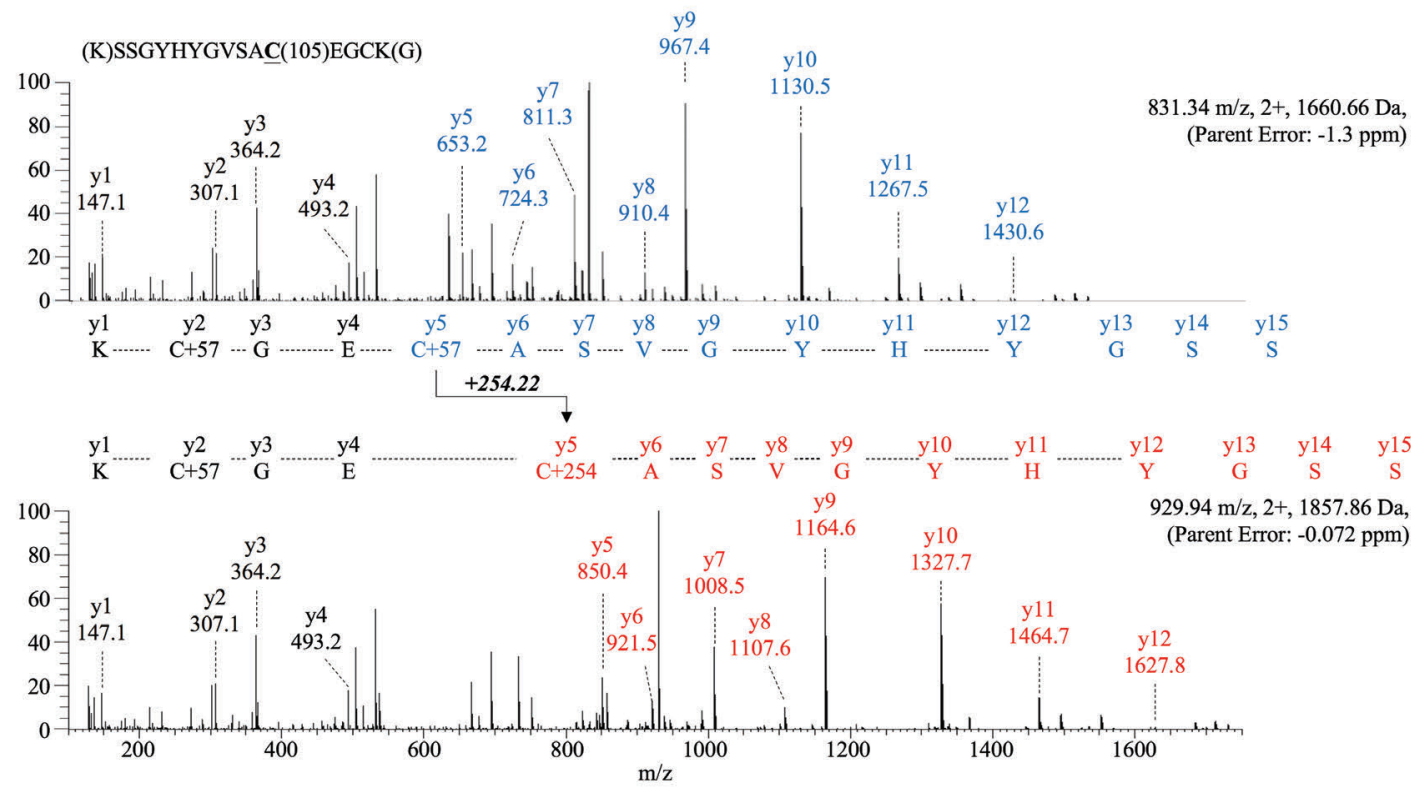

C

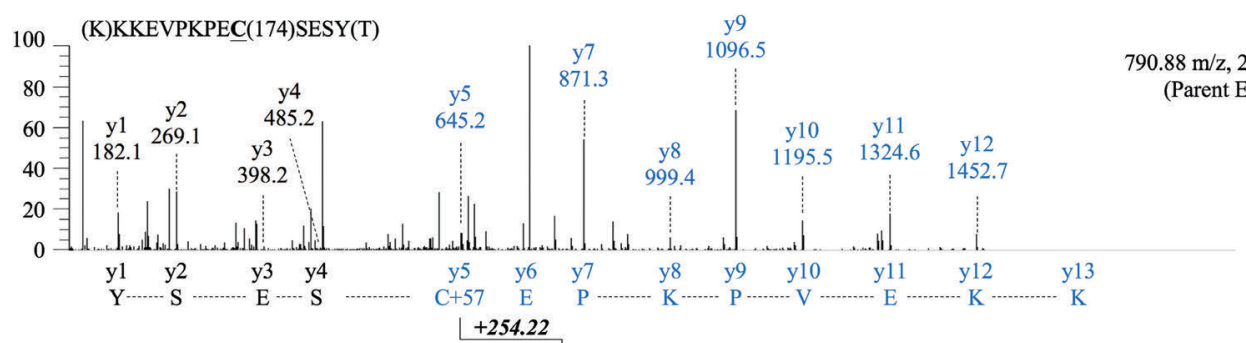

$\stackrel{+254.22}{+}$

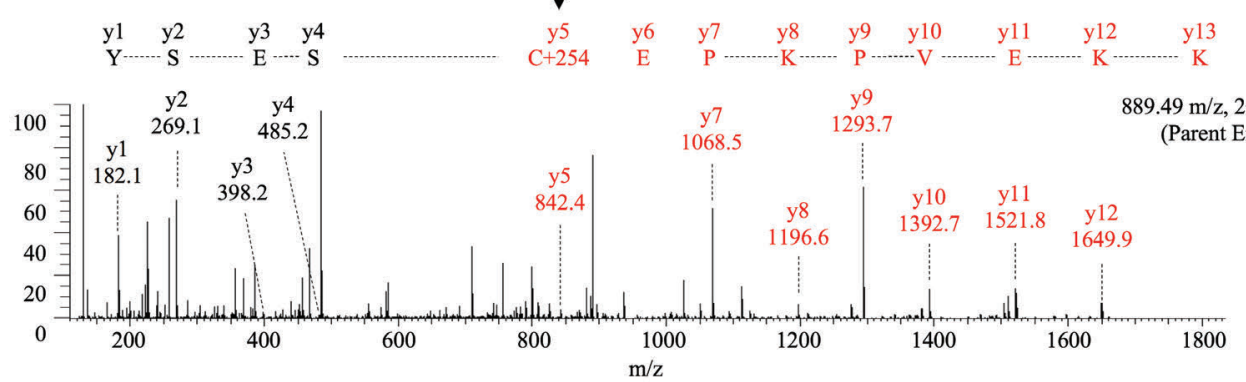

D

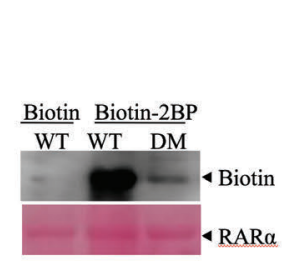

E

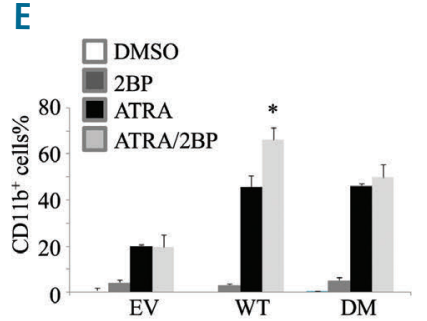

$\mathrm{F}$

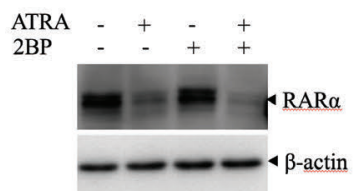

Figure 6. Identificaiton of 2BP binding sites within RAR $\alpha$. (A) Structure schematic diagram of RAR $\alpha$ protein. AF: activation function domain; DBD: DNA binding domain; LBD: ligand binding domain. (B-C) MS/MS analysis of the Cys105-(B) or Cys174- containing(C) tryptic peptide for recombinant RAR incubated without (top) and with (bottom) 2BP for 30 mins. (D) Recombinant wild-type (WT) RAR $\alpha$ and the Cys105/174 double mutants(DM) were incubated with biotin-2BP for 30 mins, followed by blotting with anti-RAR $\alpha$ antibody. The membrane stained with Ponceau S is shown at the bottom. (E) NB4 cells were infected with shRNA specifically against RAR $\alpha$ to deplete endogeneous RAR $\alpha$ and then infected with plasmids encompassing WT or DM RAR $\alpha$. These cells were treated with $5 \mu \mathrm{M} 2 \mathrm{BP}$ and/or $10^{-8} \mathrm{M}$ ATRA for 3 days and CD11b-positive cells were counted by flow cytometry. ${ }^{*} P<0.05$ against ATRA-treated group. (F) NB4 cells expressing DM RAR $\alpha$ were incubated with 5 $\mu \mathrm{M}$ of $2 \mathrm{BP}$ and/or $10^{-8} \mathrm{M}$ ATRA for 48 hours and RAR $\alpha$ protein was detected by western blot with $\beta$-actin as the loading control. 
end, cellular thermal shift assay (CETSA), a method used to evaluate the binding of compounds to target proteins in cells and tissue samples based on the biophysical principle of ligand-induced thermal stabilization of target proteins ${ }^{43,44}$ was applied in NB4 cells. We observed that 2BP treatment markedly increased the thermal stability of $\mathrm{RAR} \alpha$ protein at temperatures examined compared to vehicle treatment (Figure 5A). Furthermore, RAR $\alpha$ protein was accumulated by $2 \mathrm{BP}$ in a concentration-dependent manner (Figure 5B). Vinculin, a cytoskeletal protein associated with cell-cell and cell-matrix junctions ${ }^{45}$ and pyruvate kinase $\mathrm{M} 2(\mathrm{PKM} 2)$, a rate-limiting enzyme in glycolysis ${ }^{46,47}$ were taken as negative controls (Figure 5A-B). These data suggested that 2BP interacts with RAR $\alpha$ in APL cells.

The binding between $2 \mathrm{BP}$ and $\mathrm{RAR} \alpha$ protein was further evaluated by surface plasmon resonance (SPR) assay using a biacore platform. The sensorgrams showed that $2 \mathrm{BP}$ rapidly associated with immobilized recombinant $\operatorname{RAR} \alpha$ protein at an equilibrium dissociation constant of $28.97 \mathrm{nM}$ (Figure 5C). Moreover, the response signal during the dissociation phase did not return to the baseline level for 2BP, indicating that 2BP could not be completely eluted from RAR $\alpha$ (Figure 5C). These data suggested that $2 \mathrm{BP}$ is covalently bound to RAR $\alpha$ protein. Experiments with biotin-tagged 2BP (hereafter named biotin-2BP ${ }^{10}$ ) further supported that biotin-2BP could covalently bind with recombinant RAR $\alpha$ protein, and this binding displayed a time-dependent saturation (Figure 5D).

Mechanistically, covalent binding of 2BP with targets is more possible between the $\alpha$-halo-carbonyl group and cysteines within proteins. ${ }^{10}$ Thereafter, we compared the effect of 2BP analogs, including palmitate acid (PA), 16BP and $12 \mathrm{BP}$ with $2 \mathrm{BP}$ on ATRA-induced differentiation of APL cells. These analogs either lack a bromine atom or have a bromine atom in a different position (Figure 5E). The results showed that, unlike $2 \mathrm{BP}$, the three compounds did not present a synergistic effect with ATRA as evidenced by the percentage of CD11b-positive cells (upper panel, Figure 5F). In addition, the three compounds did not accumulate RAR $\alpha$, as 2BP did (bottom panel, Figure 5F). These data indicated that the $\alpha$-halo-carbonyl group is essential for the binding of 2BP with RAR $\alpha$.

\section{Cys 105 and Cys174 of RAR $\alpha$ is the binding site for 2BP}

To further determine the specific cysteine (Cys) residue that is modified by $2 \mathrm{BP}$ in RAR $\alpha$ protein, we purified and incubated recombinant RAR $\alpha$ protein with $2 \mathrm{BP}$, followed by mass spectrometry (MS) analysis. There are 18 cysteines located in different domains within RAR $\alpha$ protein (Figure 6A). We identified $90 \%$ of the RAR $\alpha$ protein sequence and 15 cysteine-containing peptides of the recombinant RAR $\alpha$ incubated with and without $2 \mathrm{BP}$ (data not shown). The $\mathrm{m} / \mathrm{z}$ ratio of the Cys105-containing peptide SSGYHYGVSACEGCK (Figure 6B) and Cys174-containing peptide KKEVPKPECSESY (Figure 6C) was measured as 1,660.66 and 1,579.75 in the absence of 2BP and $1,857.86$ and $1,776.96$ in the presence of $2 \mathrm{BP}$. The calculated mass shift was consistent with the addition of one molecule of 2BP. As for Cys105, MS/MS analysis of both unmodified and modified Cys105-containing peptide gave a partial series of $y$-ion fragments corresponding to the predicted sequence. Both MS/MS spectra had the same mass from $y 1$ to $y 4$, whereas the mass shifted $254.22 \mathrm{Da}$ for the Cys105-containing fragment (from y5 to y12) in the modified peptide spectra (Figure 6B)

To verify the binding of 2BP with Cys105 and Cys174, we incubated synthesized biotin-2BP with purified wildtype (WT) or Cys105/Cys174 double-mutated (DM) RAR $\alpha$ proteins. Mutation of Cys105/Cys174 remarkably diminished the binding of RAR $\alpha$ with $2 \mathrm{BP}$ in vitro (Figure $6 \mathrm{D})$, indicating that 2BP covalently modified Cys105 and Cys174 of RAR $\alpha$.

Finally, we knocked down the endogenous RAR $\alpha$ and re-expressed flag-tagged Cys105/Cys174 DM RAR $\alpha$ into NB4 cells and evaluated the effects of 2BP. The results showed that $2 \mathrm{BP}$ enhanced the differentiation effect of ATRA in RAR $\alpha$-WT expressing but not RAR $\alpha$-DM expressing NB4 cells, indicating that $2 \mathrm{BP}$ presents a synergistic effect with ATRA through binding with Cys105/Cys174 (Figure 6E). Consistent with this, DM RAR $\alpha$ could not be efficiently accumulated by 2BP in the presence of ATRA in NB4 cells (Figure 6F). Collectively, these data indicated that $2 \mathrm{BP}$ enhanced the ATRA-induced differentiation through binding to Cys105/Cys174 within $\operatorname{RAR} \alpha$ protein.

\section{Discussion}

For the past decades, much effort has been devoted to identifying novel compounds with specific targets that would maximize the therapeutic effects of ATRA. ${ }^{28,29,48,49}$ For example, our group reported that pharicin B, a novel natural ent-kaurene diterpenoid derived from Isodon pharicus leaves, stabilizes RAR $\alpha$ protein and presents synergistic differentiation induction with ATRA in AML cells. It can also overcome retinoid resistance in two ATRAresistant NB4 subclones. ${ }^{48}$ Wang et al. identified a novel synthetic small compound, named LG-362B, targeting PML-RAR $\alpha$ and blocking ATRA resistance on cellular differentiation and transplantable murine models. ${ }^{28}$ More recently, Li et al. reported that pseudokinase Tribble 3 (TRIB3) promotes PML-RAR $\alpha$-driven APL by interacting with PML-RAR $\alpha$ and disturbing the TRIB3/PML-RAR $\alpha$ interaction through an $\alpha$-helix peptide Pep2-S160 produced significant anti-APL effects. ${ }^{49}$ All these studies sought to elucidate APL pathogenesis and find more therapeutic options for APL patients.

In the present work, we have demonstrated that 2BP presents synergistic differentiation induction with ATRA in APL cell lines, primary APL blasts and in an APL murine model. Moreover, 2BP overcomes ATRA resistance both in vitro and in vivo, demonstrating therapeutic potential in APL. The cellular target of $2 \mathrm{BP}$ here, differently to previously reported CPT1 in FAO and PAT in protein palmitoylation, is RAR $\alpha$ protein which triggers differentiation of leukemia cells through transcriptional mechanism. The binding of $2 \mathrm{BP}$ with RAR $\alpha$ prevented the degradation of RAR $\alpha$ protein and sustained its transcriptional activity, leading to the differentiation-enhancing effect of 2BP. Recently, multiple investigations have indicated that RAR is a potential drug target for cancer and metabolic diseases. ${ }^{50}$ Thus, our data provides a new candidate to probe potential pathophysiological and therapeutic roles of RAR $\alpha$.

Notably, 2BP also stabilized PML-RAR $\alpha$, which was well-documented to block hematopoietic differentiation through interfering transcriptional activity of RAR $\alpha$, and the therapeutic effects of both ATRA and ATO relied on the degradation of this fusion protein..$^{15,18,51}$ However, 
forced expression of PML-RAR $\alpha$ could increase ATRA sensitivity in U937 cells ${ }^{52}$ and restore ATRA sensitivity in NB4.007/6 ATRA-resistant cells ${ }^{53}$ demonstrating a dual role for the fusion protein in leukemogenesis. On the other hand, a number of compounds capable of restraining ATRA-dependent PML-RAR $\alpha$ proteolysis have been shown to enhance ATRA-induced differentiation, ${ }^{54.57}$ indicating that a mechanism independent of PML-RAR $\alpha$ degradation that drives granulocytic maturation does exist. Therefore, how stabilized PML-RAR $\alpha$ protein contributes to 2BP-enhanced cell differentiation deserves further exploration.

Combination of ATO with ATRA serves as a frontline treatment of APL. ATO is also used as the best salvage therapy agent for ATRA-resistant APL patients. ${ }^{15,19,20,31}$ Mechanistically, ATO induced PML-RAR $\alpha$ degradation through direct binding to cysteine residues in PML moiety of the fusion protein. ${ }^{.1}$ However, resistance to ATO in APL was reported by several groups. ${ }^{2426}$ Here, we observed an increase of APL cell differentiation and leukemia mice survival upon cotreatment of ATO with $2 \mathrm{BP}$, suggesting that an approach combining ATO with 2BP warrants further investigation as a therapeutic strategy for APL patients.

The effects of 2BP on cell differentiation have been observed in neural stem cell and osteoblast. ${ }^{11-13}$ However, no direct differentiation-associated target of $2 \mathrm{BP}$ has been identified. Interestingly, different from our results, research from Chen et al. showed that $2 \mathrm{BP}$ treatment impaired ATRA-induced neuronal differentiation in vitro which involved the palmitoylation of P300 and acetylation of histones $\mathrm{H} 3$ and $\mathrm{H} 4{ }^{13}$ Further investigation of $2 \mathrm{BP}$ RAR $\alpha$ interaction in the context of neural cells may offer some clues for better understanding the controversial effect of 2BP towards ATRA.

Most of the 2BP-targeted enzymes, whether in lipid or nonlipid processing, contain cysteine residues in or near the enzyme active site, suggesting $\alpha$-halo-carbonyl electrophilic alkylation mediates the observed irreversible inhibition. ${ }^{10}$ In the present work, we identified that of all the 18 cysteines within RAR $\alpha$ sequence, Cys105 and
Cys174 are the major residues for $2 \mathrm{BP}$ binding. Substitution of WT RAR $\alpha$ with Cys105/Cys174 DM significantly decreased the synergistic differentiation activity of $2 \mathrm{BP}$ as well as the accumulation of RAR $\alpha$ protein in the presence of ATRA, indicating that despite the potential promiscuous cellular targets of $2 \mathrm{BP},{ }^{10}$ the binding of $2 \mathrm{BP}$ with RAR $\alpha$ at Cys105/Cys174 is responsible for, albeit partially, preventing ATRA-triggered degradation of RAR $\alpha$ which helps differentiation. Previous studies have showed that ATRA-triggered degradation of RAR $\alpha$ was mediated by the ubiquitin-proteasome pathway. ${ }^{34}$ Our data thus suggested that the binding of $2 \mathrm{BP}$ may influence the proteasomal degradation of RAR $\alpha$ protein.

Overall, RAR $\alpha$ modulation in the treatment of APL has generated considerable interest in the development of RAR modulators and uncovered a promising strategy for these diseases. Our discoveries demonstrate that by targeting RAR $\alpha$, 2BP not only helps ATRA-induced APL differentiation, but also reverts ATRA resistance in vitro and in vivo. Combining ATRA with $2 \mathrm{BP}$ could be a potential candidate for ameliorating ATRA-associated adverse effects and clinical relapsed APL.

\section{Acknowledgments}

The authors would like to thank Dr. Ai-Wu Zhou for his kindness in providing us the psumo 3 vector. We appreciate Dr. Weiwei Wang for his professional suggestions on identification of the binding site of $2 B P$.

\section{Funding}

This work was supported by National Natural Science Foundation (81370652, 81770146, 81721004, 81430061,81570124,31570824), National Basic Research Program of China (2015CB910403), Foundation for the author of National Excellent Doctoral Dissertation of China (201074), Grants from Science and Technology Committee of Shanghai (13431900501) and the Reformation Project in the Key Clinical Departments of Provincial Hospitals on Construction of Diagnosis and Treatment Capacity in Liaoning Province (LNCCC-A02-2015).

\section{References}

1. German NJ, Yoon H, Yusuf RZ, et al. PHD3 Loss in cancer enables metabolic reliance on fatty acid oxidation via deactivation of ACC2. Mol Cell. 2016;63(6):1006-1020.

2. Carracedo A, Cantley LC, Pandolfi PP. Cancer metabolism: fatty acid oxidation in the limelight. Nat Rev Cancer. 2013; 13(4):227-232.

3. Samudio I, Harmancey R, Fiegl M, et al. Pharmacologic inhibition of fatty acid oxidation sensitizes human leukemia cells to apoptosis induction. J Clin Invest. 2010; 120(1):142-156.

4. Farge T, Saland E, de Toni F, et al. Chemotherapy-resistant human acute myeloid leukemia cells are not enriched for leukemic stem cells but require oxidative metabolism. Cancer Discov. 2017;7(7):716735.

5. Tabe Y, Yamamoto S, Saitoh K, et al. Bone marrow adipocytes facilitate fatty acid oxidation activating AMPK and a transcriptional network supporting survival of acute monocytic leukemia cells. Cancer Res. 2017;77(6):1453-1464.

6. Spaner DE, Lee E, Shi Y, et al. PPAR-alpha is a therapeutic target for chronic lymphocytic leukemia. Leukemia. 2013; 27(5):1090-1099.

7. Chase JF, Tubbs PK. Specific inhibition of mitochondrial fatty acid oxidation by 2 bromopalmitate and its coenzyme A and carnitine esters. Biochem J. 1972;129(1):5565.

8. Burges RA, Butt WD, Baggaley A. Some effects of alpha-bromopalmitate, an inhibitor of fatty acid oxidation, on carbohydrate metabolism in the rat. Biochem J. 1968;109(3):38P-39P.

9. Martin BR, Cravatt BF. Large-scale profiling of protein palmitoylation in mammalian cells. Nat Methods. 2009;6(2):135-138.

10. Davda D, El Azzouny MA, Tom CT, et al. Profiling targets of the irreversible palmitoylation inhibitor 2-bromopalmitate. ACS Chem Biol. 2013;8(9):1912-1917.

11. Leong WF, Zhou T, Lim GL, Li B. Protein palmitoylation regulates osteoblast differ- entiation through BMP-induced osterix expression. PLoS One. 2009;4(1):e4135.

12. Chen X, Du Z, Li X, et al. Protein palmitoylation regulates neural stem cell differentiation by modulation of EID1 activity. Mol Neurobiol. 2016;53(8):5722-5736.

13. Chen X, Du Z, Shi W, et al. 2Bromopalmitate modulates neuronal differentiation through the regulation of histone acetylation. Stem Cell Res. 2014; $12(2): 481$ 491.

14. de The H, Pandolfi PP, Chen Z. Acute promyelocytic leukemia: a paradigm for oncoprotein-targeted cure. Cancer Cell. 2017;32(5):552-560

15. Wang ZY, Chen Z. Acute promyelocytic leukemia: from highly fatal to highly curable. Blood. 2008;111(5):2505-2515

16. de The H, Chen Z. Acute promyelocytic leukaemia: novel insights into the mechanisms of cure. Nat Rev Cancer. 2010; 10(11):775-783.

17. de The $\mathrm{H}$, Chomienne $\mathrm{C}$, Lanotte $\mathrm{M}$, Degos L, Dejean A. The t $(15 ; 17)$ translocation of acute promyelocytic leukaemia 
fuses the retinoic acid receptor alpha gene to a novel transcribed locus. Nature. 1990; 347(6293):558-561.

18. Dos Santos GA, Kats L, Pandolfi PP. Synergy against PML-RARa: targeting transcription, proteolysis, differentiation, and self-renewal in acute promyelocytic leukemia. J Exp Med. 2013;210(13):27932802.

19. Chen GQ, Shi XG, Tang W, et al. Use of arsenic trioxide (As2O3) in the treatment of acute promyelocytic leukemia (APL): I. As2O3 exerts dose-dependent dual effects on APL cells. Blood. 1997;89(9):3345-3353.

20. Shen ZX, Chen GQ, Ni JH, et al. Use of arsenic trioxide (As2O3) in the treatment of acute promyelocytic leukemia (APL): II. Clinical efficacy and pharmacokinetics in relapsed patients. Blood. 1997;89(9):33543360.

21. Sanz MA, Fenaux P, Lo Coco F. Arsenic trioxide in the treatment of acute promyelocytic leukemia. A review of current evidence. Haematologica. 2005;90(9):12311235.

22. Girmenia C, Lo Coco F, Breccia M, et al. Infectious complications in patients with acute promyelocytic leukaemia treated with the AIDA regimen. Leukemia. 2003;17(5):925-930.

23. Latagliata R, Petti MC, Fenu $S$, et al. Therapy-related myelodysplastic syndrome-acute myelogenous leukemia in patients treated for acute promyelocytic leukemia: an emerging problem. Blood. 2002;99(3):822-824.

24. Zhu HH, Oin YZ, Huang XJ. Resistance to arsenic therapy in acute promyelocytic leukemia. N Engl J Med. 2014; 370(19):1864-1866.

25. Lehmann-Che J, Bally C, de The H. Resistance to therapy in acute promyelocytic leukemia. N Engl J Med. 2014; 371(12):1170-1172

26. Chendamarai E, Ganesan S, Alex AA, et al. Comparison of newly diagnosed and relapsed patients with acute promyelocytic leukemia treated with arsenic trioxide: insight into mechanisms of resistance. PLoS One. 2015;10(3):e0121912

27. Lyu Y, Lou J, Yang Y, et al. Dysfunction of the WT1-MEG3 signaling promotes AML leukemogenesis via p53-dependent and independent pathways. Leukemia. 2017;31(12):2543-2551.

28. Wang X, Lin $Q$, Lv F, et al. LG-362B targets PML-RARalpha and blocks ATRA resistance of acute promyelocytic leukemia. Leukemia. 2016;30(7):1465-1474.

29. Liu CX, Yin OQ, Zhou HC, et al. Adenanthin targets peroxiredoxin I and II to induce differentiation of leukemic cells. Nat Chem Biol. 2012;8(5):486-493.

30. Brown D, Kogan S, Lagasse E, et al. A PMLRARalpha transgene initiates murine acute promyelocytic leukemia. Proc Natl Acad Sci USA. 1997;94(6):2551-2556.

31. Tong Q, You H, Chen X, et al. ZYH005, a novel DNA intercalator, overcomes alltrans retinoic acid resistance in acute promyelocytic leukemia. Nucleic Acids
Res. 2018;46(7):3284-3297.

32. Bachmann AS, Opoku-Ansah J, IbarraRivera TR, et al. Syrbactin structural analog TIR-199 blocks proteasome activity and induces tumor cell death. J Biol Chem. 2016;291(16):8350-8362.

33. Kogan SC, Hong SH, Shultz DB, Privalsky ML, Bishop JM. Leukemia initiated by PMLRARalpha: the PML domain plays a critical role while retinoic acid-mediated transactivation is dispensable. Blood. 2000; 95(5):1541-1550.

34. Zhu J, Gianni M, Kopf E, et al. Retinoic acid induces proteasome-dependent degradation of retinoic acid receptor alpha (RARalpha) and oncogenic RARalpha fusion proteins. Proc Natl Acad Sci USA. 1999;96(26):14807-14812.

35. de The $\mathrm{H}$, Vivanco-Ruiz MM, Tiollais $\mathrm{P}$, Stunnenberg H, Dejean A. Identification of a retinoic acid responsive element in the retinoic acid receptor beta gene. Nature. 1990;343(6254):177-180.

36. Matikainen S, Ronni T, Hurme M, Pine R, Julkunen I. Retinoic acid activates interferon regulatory factor-1 gene expression in myeloid cells. Blood. 1996;88(1):114-123

37. Yu M, Tong JH, Mao M, et al. Cloning of a gene (RIG-G) associated with retinoic acidinduced differentiation of acute promyelocytic leukemia cells and representing a new member of a family of interferon-stimulated genes. Proc Natl Acad Sci USA. 1997;94(14):7406-7411.

38. Davies PJ, Murtaugh MP, Moore WT, Jr., Johnson GS, Lucas D. Retinoic acidinduced expression of tissue transglutaminase in human promyelocytic leukemia (HL-60) cells. J Biol Chem. 1985; 260(8):5166-5174.

39. Kitareewan S, Pitha-Rowe I, Sekula D, et al. UBE1L is a retinoid target that triggers PML/RARalpha degradation and apoptosis in acute promyelocytic leukemia. Proc Natl Acad Sci USA. 2002;99(6):3806-3811.

40. Koeffler HP, Ranyard J, Pertcheck M Myeloperoxidase: its structure and expression during myeloid differentiation. Blood. 1985;65(2):484-491.

41. Gianni M, Li Calzi M, Terao M, et al. AM580, a stable benzoic derivative of retinoic acid, has powerful and selective cyto-differentiating effects on acute promyelocytic leukemia cells. Blood. 1996; 87(4):1520-1531.

42. Toma S, Isnardi L, Raffo P, et al. RARalpha antagonist Ro 41-5253 inhibits proliferation and induces apoptosis in breast-cancer cell lines. Int J Cancer. 1998;78(1):86-94.

43. Martinez Molina D, Jafari $R$, Ignatushchenko $\mathrm{M}$, et al. Monitoring drug target engagement in cells and tissues using the cellular thermal shift assay. Science. 2013:341(6141):84-87.

44. Jafari R, Almqvist $\mathrm{H}$, Axelsson $\mathrm{H}$, et al. The cellular thermal shift assay for evaluating drug target interactions in cells. Nat Protoc. 2014;9(9):2100-2122.

45. Huang DL, Bax NA, Buckley CD, Weis WI, Dunn AR. Vinculin forms a directionally asymmetric catch bond with F-actin.
Science. 2017;357(6352):703-706

46. Xia L, Wang XR, Wang XL, et al. A novel role for pyruvate kinase $\mathrm{M} 2$ as a corepressor for P53 during the DNA damage response in human tumor cells. J Biol Chem. 2016;291(50):26138-26150.

47. Panchabhai S, Schlam I, Sebastian S, Fonseca R. PKM2 and other key regulators of Warburg effect positively correlate with CD147 (EMMPRIN) gene expression and predict survival in multiple myeloma. Leukemia. 2017;31(4):991-994.

48. Gu ZM, Wu YL, Zhou MY, et al. Pharicin B stabilizes retinoic acid receptor-alpha and presents synergistic differentiation induction with ATRA in myeloid leukemic cells. Blood. 2010;116(24):5289-5297.

49. Li K, Wang F, Cao WB, et al. TRIB3 promotes APL progression through stabilization of the oncoprotein PML-RARalpha and inhibition of p53-mediated senescence. Cancer Cell. 2017;31(5):697-710 e697.

50. Altucci L, Leibowitz MD, Ogilvie KM, de Lera AR, Gronemeyer H. RAR and RXR modulation in cancer and metabolic disease. Nat Rev Drug Discov. 2007;6(10):793-810.

51. Zhang XW, Yan XJ, Zhou ZR, et al. Arsenic trioxide controls the fate of the PMLRARalpha oncoprotein by directly binding PML. Science. 2010;328(5975):240-243.

52. Ruthardt M, Testa U, Nervi C, et al Opposite effects of the acute promyelocytic leukemia PML-retinoic acid receptor alpha (RAR alpha) and PLZF-RAR alpha fusion proteins on retinoic acid signalling. Mol Cell Biol. 1997;17(8):4859-4869.

53. Fanelli M, Minucci S, Gelmetti V, Nervi C, Gambacorti-Passerini C, Pelicci PG Constitutive degradation of PML/RARalpha through the proteasome pathway mediates retinoic acid resistance. Blood. 1999;93(5):1477-1481.

54. Gianni M, Kalac Y, Ponzanelli I, Rambaldi A, Terao M, Garattini E. Tyrosine kinase inhibitor STI571 potentiates the pharmacologic activity of retinoic acid in acute promyelocytic leukemia cells: effects on the degradation of RARalpha and PMLRARalpha. Blood. 2001;97(10):3234-3243.

55. Finch RA, Li J, Chou TC, Sartorelli AC. Maintenance of retinoic acid receptor alpha pools by granulocyte colony-stimulating factor and lithium chloride in all-trans retinoic acid-treated WEHI-3B leukemia cells: relevance to the synergistic induction of terminal differentiation. Blood. 2000; 96(6):2262-2268.

56. Launay S, Gianni M, Diomede L, Machesky LM, Enouf J, Papp B. Enhancement of ATRA-induced cell differentiation by inhibition of calcium accumulation into the endoplasmic reticulum cross-talk between RAR alpha and calciumdependent signaling. Blood. 2003; 101(8):3220-3228.

57. Witcher M, Shiu HY, Guo Q, Miller WH, Jr. Combination of retinoic acid and tumor necrosis factor overcomes the maturation block in a variety of retinoic acid-resistant acute promyelocytic leukemia cells. Blood. 2004;104(10):3335-3342. 